\title{
AKTUALISASI AJARAN TRI HITA KARANA DALAM TRADISI TAJEN PANGANGON DI SUBAK TEBA DESA ADAT TANGEB
}

\author{
Oleh: \\ Ni Made Surawati \\ madesurawati@yahoo.co.id \\ UNHI Denpasar \\ Ida Ayu Putu Sari \\ iasari@unhi.ac.id \\ UNHI Denpasar
}

\begin{abstract}
ABSTRAK
Tradisi Tajen Pangangon merupakan tradisi unik yang terdapat di Subak Teba Desa Adat Tangeb, Mengwi, Badung. Tradisi ini dilaksanakan oleh krama 'masyarakat anggota' Subak Teba di Desa Adat Tangeb setiap satu tahun sekali, tepatnya menjelang panen padi masa 'padi yang berumur 105 hari'. Pelaksanaanya dilakukan di tiga tempat yaitu di Pura Ulun Carik, Pura Bedugul, dan Pura Bale Agung. Sarana utama yang digunakan dalam pelaksanaan tradisi Tajen Pangangon adalag ketupat dan bantal 'ketupat berbentuk lonjong panjang' yang merupakan simbol purusa dan pradhana. Ketupat dan bantal tersebut digunakan sebagai alat untuk saling lempar-melempar (matetimpugan) oleh krama subak yang dibagi menjadi dua kelompok. Dalam pelaksanaannya, konsep Tri Hita Karana digunakan sebagai landasan filosofis pelestarian tradisi Tajen Pangangon yang diperlihatkan melalui tahap persiapan hingga penutup, terutama dicerminkan dengan pola pikir pengelolaan air irigasi yang dilakukan dengan landasan harmoni dan kebersamaan antar karma dan hubungan dengan pencipta dan alam.
\end{abstract}

Kata Kunci: Tajen Pangangon, Subak, Tri Hita Karana, Desa Adat, Hindu

\section{ABSTRACT}

One of the unique tradition found in Bali is called Tajen Pangangon. This tradition is found in the Subak Teba of Tangeb Desa Adat, Mengwi, Badung. It is carried out by the community members of Subak Teba in Desa Adat Tangeb once every year, precisely before the rice harvest period of 105 days. The implementation is carried out in three places, namely Ulun Carik Temple, Bedugul Temple and Bale Agung Temple. The main means used in carrying out the tradition of the Pangangon Tajen are ketipat 'rice inside rhombus' and bantal 'elliptical shaped palm leave with rice inside' which are symbols of purusa and pradhana. The ketipat and the bantal are used as a tool for throwing each other (matetimpugan) by the subak members who are divided into two groups. In its implementation, the concept of Tri Hita Karana is utilized as a philosophical foundation for the preservation of the Tajen Pangangon tradition shown through the preparatory to the closing stages, especially reflected in the mindset of irrigation water management carried out on the basis of harmony and togetherness between people and relations with the creator and nature. 
Keywords: Tajen Pangangon, Subak, Tri Hita Karana, Desa Adat, Hindu

\section{PENDAHULUAN}

Agama Hindu dengan tiga kerangka dasarnya menyebabkannya tetap eksis di Indonesia, khususnya di Bali. Ketiga kerangka dasar itu meliputi tattwa 'filsafat', susila 'etika', dan acara 'ritual'. Ajaran tattwa dilaksanakan melalui pemahaman Panca Sradha, etika melalui Tri Kaya Parisudha dan ritual melalui pemahaman Panca Yajna. Sesungguhnya, ketiga kerangka dasar itu mempunyai korelasi yang holistik. Ibarat telor, apabila salah satu elemennya tidak ada atau rusak, tentu telor itu akan busuk, dan tidak lagi menjadi satu kesatuan yang utuh. Filsafat, etika, dan ritual sepatutnya dipahami secara bersamaan, sebab bila hanya memahami filsafat saja akan mengakibatkan kebudayaan sukar berkembang, sebaliknya bila hanya memahami etika dan ritual maka dapat menimbulkan fanatisme (Sura, 1995/1996:1).

Selain itu, ajaran agama Hindu diterapkan melalui desa, kala, dan patra yang kadang berbeda antara satu tempat dengan tempat yang lain. Dengan kata lain, faktor dresta dan desa mawecara berpotensi membuat adanya perbedaan pelaksanaan ajaran agama. Semua aktivitas umat Hindu lebih tampak dalam budaya tradisional karena telah melalui perjalanan sejarah yang panjang, sehingga masih kental tertanam pada hati nurani masyarakatnya, dan masyarakat secara turun-temurun tidak meninggalkan akar budaya yang adiluhung. Melalui konsep ini dipahami bahwa dalam pelaksanaannya, masyarakat tidak menganut paham keseragaman, melainkan keberagaman budaya. Sehingga dari situ dapat dipahami bagi masyarakat Hindu, khususnya di Bali memiliki cara-cara berbeda di masing-masing wilayah dalam keberagamaannya seseuai dengan konsensus anggota masyarakatnya. Salah satu tradisi unik dalam rangka pelaksanaan nilai-nilai Hindu Bali terdapat di Kabupaten Badung, tepatnya yang dilaksanakan oleh anggota masyarakat Subak Teba Desa Adat Tangeb. Tradisi keagamaan tersebut dikenal dengan nama Tajen Pangangon.

Tradisi Tajen Pangangon yang di jumpai di Subak Teba Desa Adat Tangeb, Mengwi, Badung, termasuk unik dan asing bagi umat Hindu yang ada di luar Desa Tangeb. Keunikannya terlihat dari sarana yang digunakan, pada umumnya bila mendengar kata tajen pasti berhubungan dengan sabung ayam, namun lain dengan tradisi Tajen Pangangon yang sarananya menggunakan ketupat dan bantal 'ketupat berbentuk lonjong panjang'. Ketupat dan bantal ini dipercayai sebagai simbul purusa dan pradhana atau roh dan tubuh dalam filsafat Hindu. Keduanya dipahami merupakan simbol kesuburan. Dalam tradisi Tajen Pangangon, ketupat dan bantal dilempar-lempar oleh kedua kelompok yang menjadi pelaksanaan tradisi ini.

Setelah pelaksanaan Tajen Pangangon selesai, ketupat dan bantal yang digunakan dipungut dan dibawa pulang oleh krama untuk diberikan kepada hewan ternak (babi dan itik). Selain dari segi sarana keunikan tradisi ini terlihat dari prosesnya yang dilaksanakan di tiga tempat yang berbeda yaitu pertama di pura Ulun Carik dengan menghaturkan piodalan alit, kedua di Pura Bedugul, dengan menghaturkan banten perani berupa ketupat dan bantal dan yang terakhir di depan Pura Bale Agung merupakan tempat pokok dari pelaksanaan tradisi Tajen Pangangon.

Tardisi Tajen Pangangon dilaksanakan setiap satu tahun sekali. Pada saat panen masa (usia padi sekitar 105 hari). Krama Subak Teba di Desa Adat Tangeb melaksanakan tradisi Tajen Pangangon dengan tujuan memohon keselamatan dan 
kesuburan tanaman padi kehadapan Ida Sang Hyang Widhi Wasa, dalam manifestasi Beliau sebagai Dewi Sri.

\section{PEMBAHASAN}

Tajen Pangangon adalah salah satu ungkapan rasa syukur krama subak khususnya kepada Ida Sang Hyang Widhi Wasa karena sudah menganugrahkan keselamatan, kesuburan dan panen yang berlimpah kepada kepada masyarakat khususnya masyarakat Tangeb. Tradisi Tajen Pangangon dilaksanakan ketika hari purnama menjelang panen padi masa (usia padi sekitar 105 hari) dan dilaksanakan setiap satu tahun sekali.

Jika tidak tepat dengan hari purnama tradisi Tajen Pangangon bisa dilaksanakan pada hari-hari seperti buda umanis, buda cemeng, buda kliwon berdasarkan kalender Bali dan hari-hari baik menurut Hindu. Alasan dilaksanakannya pada hari purnama adalah karena masyarakat atau krama subak mempercayai pada hari purnama atau bulan penuh merupakan hari yang sangat suci dan tepat untuk melaksanakan upacara yadnya yaitu Dewa Yadnya.

\subsection{Pelaksanaan Tradisi Tajen Pangangon Pelaksanaan tradisi Tajen} Pangangon dilaksanakan di tiga tempat yaitu: (1) Pura Ulun Carik yang merupakan pura yang memiliki penyiwi (pendukung atau jamaahnya) adalah masyarakat yang mata pencahariannya sebagai petani. Pura Ulun carik ini terletak di bagian hulu suatu persawahan. Di Pura Ulun Carik dihaturkan atau dipersembahkan upacara berupa banten piodalan alit yang sarananya (upakara) mencakup ayaban tumpeng pitu. (2) Pura Bedugul sebagai tempat dilakukan upacara maprani 'upacara setiap purnama' oleh krama subak. (3) Di depan Pura Bale Agung, disinilah pokok pelaksanaan Tajen Pangangon dalam bentuk metetimpugan tipat bantal 'saling melempari ketupat dan bantal' dilaksanakan. Seluruh krama subak berkumpul untuk mengikuti ritual sebelum tradisi Tajen Pangangon dilaksanakan.

Alasan pelaksanaan tradisi Tajen Pangangon dilaksanakan di depan pura Bale Agung karena di pura Bale Agung merupakan tempat berstananya semua para Dewa atau Bhatara yang digambarkan dengan konsep Dewata Nawa Sanga. Sehingga sangat tepat dilaksanakan di depan Pura Bale Agung agar kegiatan tradisi Tajen Pangangon secara niskala dapat disaksikan oleh Bhatara. Dengan demikian, diyakini oleh masyarakat bahwa para Dewa akan menganugerahkan keselamatan dan kesuburan bagi tanaman padi di sekitar Subak Teba Desa Adat Tangeb.

\subsection{Sarana dan Proses Pelaksanaan Tradisi Tajen Pangangon}

Tradisi Tajen Pangangon di Subak Teba Desa Adat Tangeb menggunakan sarana upakara atau banten yang terdiri atas:

1. Peras daksina

Perasnya berisi: taledan peras, tumpung dua buah, pisang, jajan, tebu, tingkih, dengan lauk pauknya, sampian peras (bunga, plawa, porosan, kembang rampai). Daksina alasnya memakai wakul daksina, wakul masrembeng, di dalamnya secara berturut-turut diletakkan tampak dara, base tampelan, beras, benang, uang kepeng kelapa sebutir yang telah dibersihkan serabutnya, kemudian disekitarnya dengan dialasi kojong masing-masing berupa telur itik mentah, tangkih, pangi, pisang, plawa peselan, gegantusan, bijaratus, di atasnya diletakkan canang genten atanding.

2. Banten yunan atau sodan putih kuning terdiri atas: dua punjung nasi, (satu putih, satu kuning), jajan, pisang, tangkih canang. 
3. Rayunan terdiri dari: nasi mesasah (diratakan) dengan lima takir berisi kacang, sayur ikan, daging, sambel, garam, sesaur, canang sari, lembaran.

4. Banten dapetan tumpeng pitu yang terdiri dari: taledan, tumpeng, sampian teteg, sesapi, sampian peras, sampian pengambian, jaet/guak kokokan, sampian penyeneng dan pengeresikan.

5. Banten sorohan terdiri dari: aled sorohan, tumpeng kecil sepuluh, sampian peras tiga, tangkih tiga, teteg soroan dan sampian penyeneng.

6. Penyeneng dengan upakaranya: benang tebus, daun dadap ditumbuk, tepung tawar, basma tatakan penyeneng berisi beras dan uang kepeng.

7. Pengeresikan dengan upakaranya: jajan begina dibakar (sisig) daun pucuk halus, tepung, burat wangi, minyak kelapa dengan kapas, canang.

8. Tabuh tuak, arak, berem dan tirta yang sudah disucikan.

9. Segehan cacahan dengan upakaranya: peneknya lima dengan isinya, nasi, saur, serta lauk pauk, tangkih yang di tengahnya berisi beras, benang, base ambungan, gantusan, segehan cenik putih kuning, bawang jahe dan canang.

10. Banten pepranian oleh krama subak dengan upakaranya adalah ketupat dan bantal. Pada umumnya masyarakat di Bali banyak mengenal jenis ketupat atau tipat di antaranya ketupat nasi, gong, sirikan, cakra, taluh, sari, sidakarya, sidapurna, dampulan, kukur, bagia, pengambean, sesapi, dan lain-lain. Menurut Putra, ketupat yang dipakai dalam tradisi Tajen Pangangon adalah ketupat nasi, sebagai simbol pradhana dan bantal sebagai simbol purusa. Masing-masing banten prani krama subak berisi satu kelan (6 buah) ketupat dan bantal setengah dihaturkan untuk Tajen Pangangon dan setengahnya lagi dibawa pulang oleh krama subak. Ketupat dan bantal inilah yang dipakai sebagai sarana pokok Tajen Pangangon Adapun rangkaian tradisi Tajen Pangangon yang dilakukan oleh krama Subak Teba di Desa Adat Tangeb dimulai dari menggarap sawah atau turun ke sawah adalah:

1. Ngadangin yaitu memulai bekerja di sawah. Sebelum mulai bekerja terlebih dahulu dihaturkan upakara atau banten sebagai sarana untuk memohon restu keselamatan, upacara disesuaikan dengan Pancawara yaitu:

a. Pada hari Umanis: memakai tumpeng putih dilengkapi raka geti-geti canang burat wangi lenge wangi dihaturkan menghadap ke timur.

b. Pada hari Pahing: memakai tumpeng merah dilengkapi raka geti-geti canang burat wangi lenge wangi dihaturkan menghadap ke selatan.

c. Pada hari Pon: memakai tumpeng kuning dilengkapi raka geti-geti canang burat wangi lenge wangi dihaturkan menghadap ke barat.

d. Pada hari Wage: memakai tumpeng hitam dilengkapi raka geti-geti canang burat wangi lenge wangi dihaturkan menghadap ke utara.

e. Pada hari Kliwon: memakai tumpeng brumbun dilengkapi raka geti-geti canang burat 
wangi lenge wangi dihaturkan menghadap ke tengah-tengah.

2. Ngawit nambah yaitu upacara ngatur piuning ring ibu pertiwi, Bantennya: Canang genten duang tanding, tempatnya di pengalapan sawah.

3. Mawinih mwang Ngurip Pari (mulai menanam bibit/benih padi). Biji-biji padi yang akan dipakai sebagai bibit diperciki air cendana dan air kumkuman sebagai sarana pembersihan dan penyucian. Setelah selesai dihaturkan upakara berupa segehan (nasi putih kuning) akojong maulam taluh, udang magoreng, medaging sambel kecap, sawur kelapa gading, beras kuning, sekar sarwa kuning bilih sida antuk dagingin sekar tigang kancu.

4. Nandur yaitu upacara pada waktu menanam padi yang disebut dengan upacara nuwasin, bantennya: cau petik 5, cau numbal 1, suyuk 11, penyeneng, pabersihan, canang biasa atanding.

5. Mareteka tandur yaitu upacara yang sesudah padi ditanam yang terdiri dari:

a. Sesudah 12 hari atau upacara ngeroras lemengin, yaitu upacara negteg atma pramaning pantun. Bantennya: nasi tulung 5 tanding, ketipat pandawa 2, canang saha soda, tempatnya di pengalapan 'tempat memanen' sawah atau carik.

b. Tanduran matuwuh asasih, yaitu upacara satu bulanan. Bantennya: ketipat dampulan, penek putih kuning, nasi takilan, canang tubungan lan asep.

c. Tanduran matuwuh duang sasih, yaitu upacara dua bulanan atau upacara padi menek truna. Bantennya: canang lenga wangi, burat wangi, tadah sukla atanding, blayag enem bungkul, isih-isih, klungah kirasturi lan penyeneng.

d. Tanduran tigang bulan, yaitu upacara nanggap padi wayah. Bantennya: jerimpen, sesayut katutuan, tulung limang tanding, pujung asep lan canang (Suandra, 1978 : 17-20).

Sesudah upacara tigang sasih atau nanggap padi wayah lalu dilaksanakan Upacara Masaba yang dilanjutkan dengan melaksanakan Tajen Pangangon. Pelaksanaan tradisi Tajen Pangangon dimulai di Pura Ulun carik, disana menghaturkan pengodalan dengan sarana upakara atau banten yaitu: suci, peras daksina, ajengan, tumpeng solas, soroan, datengan, prayascita, byakaonan, jerimpen, penyeneng, pengeresikan, dan penastan.

Setelah selesai menghaturkan piodalan di Pura Ulun Carik wangsuhpada Ida Bhatara (tirtha) dibawa ke Pura Bedugul. Upacara selanjutnya dilaksanakan di Pura Bedugul dengan mengadakan upacara pengusaban. Dengan menghaturkan upakara atau banten berupa: byakala, prayascita, peras daksina suci, rayunan putih kuning, dapetan, ayaban tumpeng solas, banten pengerebuan dilengkapi babi guling, cau petik, cau mumbul, penyeneng, pengeresikan, tabuh, penastan, segehan cacah, dan banten prani yang dilengkapi dengan ketupat dan bantal oleh krama subak.

Upacara dan upakara yang dilaksanakan di Pura Bedugul dipersembahkan kehadapan Ibu Pertiwi, Bhatara Wisnu, Bhatara Uma, Bhatara Sri sebagai ucapan terima kasih atas limpahan amerta kehidupan berupa padi. Juga terkandung makna memohon agar Beliau tetap melimpahkan hasil bumi berupa pangan yang tidak pernah habis-habisnya.

Setelah upakara atau banten dihaturkan oleh pemangku, banten prani 
yang berisi ketupat dan bantal diambil dan dikumpulkan oleh Pekaseh 'kepala subak' yang kemudian dibawa ke Pura Bale Agung dengan melaksanakan upacara matur piuning di Pura Bale Agung agar Beliau yang berstana di Pura Bale Agung memberikan keselamatan saat tradisi Tajen Pangangon berlangsung. Ketupat dan bantal tadi diupacarai lagi untuk memohon restu kepada Ida Hyang Bhatara Sri karena beliau merupakan Dewi Kesuburan yang merupakan Dewi Padi. Kemudian ketupat dan bantal dibawa ke jaba 'luar/pekarangan' Pura Bale Agung, sebelum tradisi Tajen Pangangon dilaksanakan terlebih dahulu krama subak sebagai peserta Tajen Pangangon diperciki tirtha yang sudah dimohon di Pura Kahyangan Tiga (Desa, Puseh dan Dalem), dan Pura Ulun Carik, Pura Bedugul dan Pura Persimpangan Batu Ngaus yang terdapat di Pura Puseh, dengan harapan upacara ini dapat berlangsung dengan lancar tanpa adanya halangan.

Usai diperciki tirtha, ketupat dan bantal dibagikan oleh panglima kepada krama subak. Pekaseh sebagai pemimpin dalam tradisi Tajen Pangangon memberikan peraturan atau tata tertib sebelum tradisi berlangsung diantaranya: tidak boleh melempar melewati garis tengah arena, tidak boleh melempar musuh pada bagian tubuh dari dada sampai kepala. Selesai dibacakan tata tertib, tradisi Tajen Pangangon (metetimpugan) segera dimulai krama subak dibagi menjadi dua kelompok, kelompok satu berada di sebelah selatan dan kelompok dua berada di utara. Terlaksanalah tradisi Tajen Pangangon yang berlangsung sekitar 10-15 menit.

Berdasarkan suatu tradisi yang terjadi di Subak Teba Desa Adat Tangeb, dapat dipahami bahwa masyarakat merupakan wadah dari pergaulan manusia yang merupakan realitas dari hakekat manusia sebagai mahluk sosial. Masyarakat lebih banyak melakukan pergaulan manusia yang dijunjung oleh sistem tertentu yang pada dasarnya kepentingan masyarakat atau demi terciptanya keselarasan hubungan antar individu dengan masyarakat. Di samping itu, setiap individu pada hakikatnya menjalani proses memanusiakan dirinya sebagai kosekuensi dari hakekat manusia sebagai mahluk sosial kemudian menjadi pendorong, penggerak hati nurani manusia untuk berkelompok, dan berinteraksi satu sama lainnya dan membentuk kesatuan masyarakat. Kehidupan individu adalah kehidupan yang diutamakan untuk mengabdi kepada masyarakat, pergaulan yang mengarah kepada saling ketergantungan, saling mempengaruhi sehingga merupakan suatu hal yang wajar apabila di dalamnya tumbuh rasa kebersamaan. Manusia tidak hidup dengan dirinya sendiri, melainkan diperuntukkan untuk mengabdi kepada masyarakat.

Tiga unsur mendasar yang digunakan sebagai landasan pencapaian kesejahteraan dan kebahagiaan dalam agama Hindu adalah Tri Hita Karana yang terdiri atas Parahyangan sebagai konsep hubungan harmonis manusia dengan Tuhan, Pawongan sebagai pertalian yang selaras antar krama dan Pelemahan sebagai ungkapan hubungan harmonis dengan alam dan lingkungan.

Apabila membicarakan karakteristik masyarakat tentunya akan mengarah pada konsep Tri Hita Karana yaitu Pawongan. Karakteristik masyarakat yang dimaksud adalah krama Subak Teba di Desa Adat Tangeb yang pada umumnya bekerja sebagai petani atau masyarakat yang mengolah lahan sawah. Karakteristik krama Subak Teba di Desa Adat Tangeb dicerminkan dengan pola pikir pengelolaan air irigasi yang dilakukan dengan landasan harmoni dan kebersamaan. Air dianggap sangat bernilai dan dihormati, serta dianggap sebagai karunia dan ciptaan Tuhan Yang Maha Esa. Oleh karena itulah, subak 
menyelenggarakan upacara khusus untuk menghormati keberadaan air, yang disebut dengan upacara mendak toyo (Windia, 2006:13).

Agama Hindu Bali sangat menghormati keberadaan air dan akhirnya agama Hindu dikenal dengan agama Tirtha. Masyarakat Bali percaya bahwa air sebagai wujud dari Dewa Wisnu, dan Dewa Wisnu adalah salah satu manifestasi dari Tuhan Yang Maha Esa yang dipercaya sebagai pemelihara kehidupan di dunia. Istri dari Dewa Wisnu adalah Dewi Sri, yang dalam kehidupan sehari-hari dianalogikan dengan padi. Tentu saja tanaman padi tidak bisa dilepaskan dengan aktifitas petani. Itulah sebabnya para petani di Bali yang tergabung dalam subak sangat menghormati keberadaan air dan tanaman padi, yang diwujudkan dengan berbagai upacara atau tradisi salah satunya tradisi Tajen Pangangon yang dilaksanakan oleh krama subak Teba di Desa Adat Tangeb yang memepunyai tujuan sebagai ungkapan rasa syukur atas panen padi yang berlimpah.

Sementara itu karakteristik krama Subak Teba di Desa Adat Tangeb dalam subsistem sosial dicerminkan dengan adanya organisasi subak yang disesuaikan dengan kepentingan masyarakat (petani) setempat, dan disesuaikan pula dengan tujuan-tujuan yang harus dicapai seperti yang diuraikan dalam konsep pola pikir yang dianut. Struktur organisasi subak pada umumnya berbeda setiap subak, tergantung antara lain dari luasnya areal subak, ketersediaan air irigasi dan kegiatan yang harus dilakukan oleh subak seperti kegiatan yang dilakukan krama Subak Teba di Desa Adat Tangeb yaitu tradisi Tajen Pangangon.

Setiap kegiatan keagamaan ataupun adat pasti mempergunakan sarana pendukung, sarana-sarana yang dipergunakan tentu memiliki kedudukan yang sangat penting, karena setiap upacara tersebut memiliki makna dan nilai tersendiri.
Dalam tradisi Tajen Pangangon tersirat beberapa nilai pendidikan diantaranya:

\subsection{Nilai-Nilai Keagamaan Hindu dan Sosial dalam Tradisi Tajen Pangangon 2.3.1 Nilai Tattwa}

Tattwa berasal dari kata tat (hakikat, kebenaran, dan kenyataan) dan twa (yang bersifat). Jadi tattwa berarti hakikat, kenyataan, kebenaran, hakikat dari objek yang kongkrit, dari sari ajaran (2005 : 127). Nilai tattwa yang terkandung dalam pelaksanaan tradisi Tajen Pangangon adalah berkaitan dengan keyakinan dan kepercayaan masyarakat subak teba di Desa Adat Tangeb mengenai keberadaan tradisi tersebut. Tradisi merupakan suatu kebiasaaan yang diwariskan oleh leluhur kepada masyarakatnya, dengan berbagai nilai yang terkandung di dalamnya sebagai pedoman untuk berprilaku dalam masyarakat.

Tradisi Tajen Pangangon dilaksanakan setiap satu tahun sekali saat musim panen padi tiba. Masyarakat memiliki kepercayaan bahwa melalui pelaksanaan Tajen Pengongon mampu mempersatukan masyarakat khusunya krama subak dan juga sebagai tempat berkumpul, sehingga tetap terjalin hubungan yang harmonis sesama krama. Sedangkan secara niskala, Tajen Pangangon merupakan media untuk mengucapkan rasa syukur masyarakat atas anugrah Ida Sang Hyang Widhi Wasa. Dipilihlah sarana ketupat dan bantal sebagai sarana dalam Tajen Pangangon adalah karena ketupat dan bantal melambangkan purusa dan pradhana, jika purusa dan pradhana dapat bertemu atau bersatu akan menimbulkan kesuburan

\subsubsection{Nilai Estetika}

Ditinjau dari etimologinya kata estetika berasal dari bahasa Yunani yaitu "aesthesis" yang berarti perasaan atau 
sensitivitas. Setiap umat beragama mempunyai rasa keindahan yang kadangkala berbeda rasa penuangan keindahannya. Disini tidak membahas mengenai realisasi rasa keindahan semua agama, namun yang dibahas hanya mengenai rasa keindahan bagi agama Hindu dalam hubungannya untuk mewujudkan rasa bhaktinya kehadapan Ida Sang Hyang Widhi Wasa maupun manifestasinya tampak dalam berbagai karya seni yang mempunyai nilai religius dan filosofinya yang tinggi.

Begitu pula di dalam pelaksanaan tradisi Tajen Pangangon biasanya terdapat perlengkapan upacara seperti jenis-jenis jejaitan 'daun yang dibentuk dan dijarit' dengan bermacam-macam reringgitan yang mana reringgitannya tersebut merupakan perwujudan dari rasa keindahan atau estetika. Rasa keindahan ini biasanya melahirkan seni budaya yang mengamalkan nilai-nilai luhur agama Hindu.

Peralatan atau sarana yang dipergunakan dalam setiap pelaksanaan tradisi Tajen Pangangon mempunyai nilainilai keindahan yang dinikmati oleh panca indra misalnya banten-banten yang dipergunakan dalam tradisi Tajen Pangangon yang berisi berbagai macam dan bentuk reringgitan, yang memiliki suatu kekuatan seni dan kharisma yang membangkitkan ilustrasi pandangan, seolaholah ada kehidupan dalam upakara tersebut.

\subsubsection{Nilai Etika}

Nilai etika yang dimaksud dalam pelaksanaan tradisi Tajen Pangangon adalah keterkaitan dengan tingkah laku manusia yang dijadikan pedoman dalam melakukan kewajiban berupa hubungan yang selaras denga Ida Sang Hyang Widhi Wasa sebagai pencipta, antara sesama manusia, dan dengan lingkungan. Pada saat pelaksanaan tradisi Tajen Pangangon krama subak menggunakan pakian adat madya. Hal ini karena peserta atau krama yang mengikuti tradisi tersebut menaati perturan yang ada bahwa setiap pelaksanaan suatu upacara keagamaan maupun tradisi keagamaan selalu mempergunakan pakian adat. Dengan menaati dan mematuhi ketentuan-ketentuan serta peraturan-peraturan yang telah ditetapkan dalam ajaran Agama Hindu, misalnya cara berpakian akan menjadi pandangan dan ukuran baik buruknya pribadi seseorang

Manusia dilengkapi dengan kemampuan berwiweka, maka dari itu diharapkan bisa memilih yang baik dan benar, sehingga mampu menghindari yang buruk dan salah. Manusia harus bisa mengendalikan diri dalam segala hal, baik dalam berpikir, berkata dan berbuat, agar dapat tercapai hal-hal yang baik dalam kehidupan.

Pengendalian diri yang ditekankan dalam hal ini adalah mampu mengusai sifat marah, yang dalam ajaran Agama Hindu disebut dengan krodha. Pengendalian diri untuk tidak marah (akrodha) dalam pelaksanaan Tajen Pangangon terlihat ketika para krama subak yang menjadi sasaran utama saat perang ketupat dan bantal diharapkan mampu mengendalikan amarahnya meskipun para krama subak harus menahan sakit karena terkena serangan dari lawan, sehingga tidak terjadi perkelahian dalam pelaksanaan tradisi tersebut.

\section{Nilai Gotong Royong dan Kebersamaan}

Gotong royong merupakan suatu kegiatan atau pekerjaan yang dilakukan oleh banyak orang dengan cara saling bantu membantu atau saling tolong menolong satu dengan yang lainnya, sehingga sebesar atau seberat apapun pekerjaan yang dilaksanakan dapat diselesaikan dengan baik.

Berdasarkan hal tersebut di atas, maka nilai gotong royong dalam pelaksanaan Tajen Pangangon terlihat ketika adanya interaksi antara masyarakat 
yang turut membantu mulai dari mempersiapkan sarana yang akan digunakan untuk pelaksanaan tradisi tersebut. Mulai pelaksanaan gotong royong (saling membantu) dalam menjalankan suatu upacara keagamaan ataupun tradisi tidak hanya merupakan wujud menciptakan hubungan yang harmonis antara sesama manusia, namun juga merupakan salah satu wujud bhakti manusia kepada Ida Sang Hyang Widhi.

Nilai kebersamaan ini tercermin dalam solidaritas krama subak Teba di Desa Adat Tangeb yang tinggi. Kebersamaan itu tercermin dalam pelaksanaan tradisi Tajen Pangangon dimana tukang banten (srati) menyiapkan sesajen (banten) yang akan digunakan, pemangku sebagai pemimpin upacara. Dengan tidak langsung tradisi Tajen Pangangon merupakan ajang bertemunya dan berkumpulnya krama subak Teba di Desa Adat Tangeb untuk bekerja sama dan mendukung pelaksanaan tradisi Tajen Pangangon agar dapat berjalan dengan lancar dan tidak mengalami hambatan apapun.

\section{PENUTUP}

Tradisi Tajen Pangangon dimaksudkan untuk memohon kepada Ida Sang Hyang Widhi Wasa khususnya Dewi Sri yang dipuja sebagai pemberi anugrah di persawahan agar berkenan memberikan anugrah sehingga hasil panen padi para petani subur dan berlimpah. Segala kegiatan yang dilaksanakan pada tradisi Tajen Pangangon mempunyai tujuan untuk menjaga keharmonisan dan keselarasan diantaranya keselarasan hubungan dengan Tuhan, dengan alam lingkungan dan juga keselarasan antara masyarakat atau karama subak teba di Desa Adat Tangeb.

\section{DAFTAR PUSTAKA}

Puja, G. 1997. Sarasamuscaya. Surabaya: Paramita.

Sri Arwati, Ni Made. 2007. Upacara Bercocok Tanam di Sawah, ; Denpasar

Suandra I Made. 1978. Tuntunan Gunan Ing Pasawahan, Tabanan : Parisdha Hindu Dharma Kabupaten Tabanan..

Sudarsana I.B. Putu. 1998. Filsafat Yadnya, Denpasar: Yayasan Dharma Acarya

Sukrawati, Ni Wayan, dkk, 2006. Kaedah Beryajnya, Orang-orang Suci dan Tempat Suci, Denpasar: Paramita.

Suprayoga, Imam dan Tambroni. 2001. Metode Penelitian Sosial - Agama, Bandung: PT. Remaja Rosdakaraya.

Sura, I Gede dkk, 2002. Alih Aksara dan Terjemahan Tutur Gong Besi Tutur Lebur Gangsa Tutur Angkus Prana, Denpasar: Dinas Kebudayaan Propinsi Bali.

Sura, I Gede dkk, 1981. Tattwa Darsana, Denpasar: PGA Hindu Negeri Denpasar. 
Triguna Ida Bagus Yudha, 1994. Pergeseran Dalam Pelaksanaan Agama Menuju Tattwa, Denpasar: BP.

Windia, Wayan. 2006. Transformasi Sisitem Irigasi Subak yang Berlandaskan Konsep Tri Hita Karana, Denpasar: Pustaka Bali Post. . 1998. Awig-awig Desa Adat Tangeb, Desa Adat Tangeb . 2011 Eka Likita Subak Teba Pesedahan Yeh Penet, Kelurahan Abianbase, Mengwi, Badung.

. 2011. Awig-awig Subak Teba Pesedahan Yeh Penet, Kelurahan Abianbase, Mengwi, Badung. 